\title{
A Study of Culture Teaching in College English Teaching
}

\author{
Liangguang Huang \\ English Department, Zhenjiang Watercraft College of PLA, Zhenjiang 212003, China \\ Email: Blackhawk1975@126.com \\ Runjiang Xu \\ English Department, Zhenjiang Watercraft College of PLA, Zhenjiang 212003, China \\ Email: Runjiangxu@126.com
}

\begin{abstract}
Language and culture are intertwined and language is an inseparable part of culture. Language, as the carrier of culture, is influenced and shaped by culture, it reflects culture and plays a very important role in it. Because of different cultural backgrounds, misunderstandings often arise among people who speak different languages even there are not any grammatical mistakes in their conversation, thus intercultural communication failure occurs. With the development of economic globalization, intercultural communication is greatly increasing. More and more foreign language educators have realized that we should attach more importance to culture in our foreign language teaching and a new term "culture teaching" is introduced. We should have correct attitudes towards language and culture, towards language teaching and culture teaching. At the same time, we should be fully aware that putting culture teaching in English teaching practice is still a challenging task and it still has a long way to go. Not only relevant scholars and experts but also common English language teachers should have a clear macroscopical grasp of culture teaching in order to cultivate students', especially non-English major students' intercultural communicative competence to catch up with the development of the world.
\end{abstract}

Index Terms - language, culture, language teaching, culture teaching, intercultural communicative

\section{INTRODUCTION}

Foreign language learning is comprised of several components, including grammatical competence, communicative competence, language proficiency, as well as a change in attitudes towards one's own or another culture. For scholars, cultural competence, that's the knowledge of the conventions, customs, beliefs, and systems of meaning of another country, is indisputably an integral part of foreign language learning, and many teachers have seen it as their goal to integrate the teaching of culture into the foreign language curriculum. At any rate, foreign language learning is foreign culture learning. As a matter of fact, culture has, even implicitly, been taught in the foreign language classroom from many aspects and for different reasons. What is debatable, though, is what is meant by the term "culture" and how culture is integrated into language learning and teaching.

In China the term "culture teaching" was first officially presented in the early 1990s, the concept of culture teaching is based theoretically on people's new cognitions of linguistic functions and the latest research production of the relationship between language and culture. While in practice, it resulted from the introduction and reference of the new teaching ideas and methodologies in the foreign countries, especially the former Soviet Union, America, British and Germany. In terms of the development of FLT in China, culture teaching is undoubtedly a great shock to our teaching idea, teaching conception, teaching content and teaching methodology from 1980s.

\section{LANGUAGE AND CULture}

With the development of global economy and the increasing communication among different countries and peoples, "culture" has become a hot topic. At the same time, the relationship between language and culture has been a focus of attention from a variety of disciplinary perspectives for many years. Linguists, anthropologists, sociologists, psychologists, and others have sought to understand whether and how cultural factors influence aspects of human behavior such as perception, cognition, language, and communication. Within language teaching, cultural factors have occasionally attracted the interest of both theoreticians and practitioners. Robert Lado was one of the first to suggest that cultural systems in the native culture could be compared with those in the target culture and serve as a source of transfer or interference in much the way other types of contrasting Linguistic systems do. Others have examined a range of different aspects of second language use that are subject to culturally based influences, including classroom interaction, roles of teachers and students, and teaching styles.

A. Definitions of Culture 
It is fashionable these days to talk about culture. Culture has become an interdisciplinary word. Every discipline seems to have something to do with culture, such as culture and society, culture and economy, culture and politics, culture and nature, etc. Culture appears to be the most frequently seen or heard word in the modern times. But what's culture?

In Raymond Williams' (1983) opinion, culture is one of the two or three most complicated words in the English language. According to his analysis, this is so partly because of its intricate historical development in several European languages; and partly because it has now come to be used for important concepts in several distinct intellectual disciplines and in several distinct and incompatible systems of thought. Scholars, in various disciplines, such as linguists, anthropologists, sociologists, psychologists, all tried to define it from different aspects.

Culture is viewed as communication and all that people of a particular culture use to communicate, namely language, verbal and nonverbal, including a variety of forms: body movement, eye contact, time, space, smells, touching, and the use of the social situation.

Culture is viewed as a general concept, without reference to any specific culture. This view is prevalent in intercultural education and training and consists of culture-general components that apply to any and all cultures.

Culture is viewed in terms of intercultural communication, the capacity and ability to enter other cultures and communicate effectively and appropriately, establish and maintain relationships, and carry out tasks with people of these cultures.

We can see from the above that up till now, linguists, anthropologists and other experts have given many kinds of definitions about culture; each has its own focus in a particular aspect.

\section{B. Language and Language Learning}

As we all know, it is language that distinguishes us from animals. Then what's language? Webster's New World dictionary offers several most frequently used senses of the word "language". To give the barest of definition, language is a means of verbal communication. As the main channel through which human beings make contact with each other, language is the most easily felt and seriously considered barrier for intercultural communicators. Students struggling with a different language are widely aware of the trouble brought about by the strange ways of expressing meanings: vocabulary, syntax, idioms, slang, dialects and so on. However, learning a language is one thing, and using it is another. We do not deny the importance of acquiring vocabulary and grammar but the application of one's knowledge of a language to specific situations is far more complicated than language learners expect. There is a kind of tenacity with which one will cling to just one meaning of a word or phrase in the new language, regardless of the connotation or context.

Learning a foreign language well means more than merely mastering the pronunciation, grammar, words and idioms. It means learning also to see the world as native speakers of that language see it, learning the ways in which their language reflects the ideas, customs, and behavior of their society, 1eaming to understand their "1anguage of the mind". Learning a language, in fact, is inseparable from learning its culture.

\section{Relationship between Language and Culture}

It has become axiomatic to state that there exists a close relationship between language and culture. It has long been recognized that language is an important part of a given culture and that the impact of culture upon a given language is something intrinsic and indispensable. More evidence can be gathered to substantiate the close relationship between language and culture if we have a brief survey of what has happened in the field of linguistics over the past century.

Admittedly, ever since the beginning of the 18th century, the linguistic inquiry of language has been either comparative and historical or structural and formalized in nature, some change, however, was observed at the start of the 20th century: an anthropological orientation in the study of language was developed both in England and in North America. What characterized this new tradition was its study of language in a sociocultural context. While Bronislaw Malinowski and John P. Firth can be regarded as the pioneers of this movement in England, Franz Boas, Edward Sapir, and Benjamin Lee Whorf are naturally seen as the representatives of a parallel but independent tradition from North America.

Those anthropologists began to make substantial contributions to the study of the relationship between language and culture around the early 1920s.From the 1920s to the 1940s, when engaged in a demanding but significant task -- the reconstruction of American Native languages, they came to know the significance of culture in the study of language use. Their anthropological approach to the study of language and culture laid a firm foundation in the history of 1inguistic development.

With their innovation, commitment, and perseverance, a lot of important and creative work has been done in the research of the relationship between language and culture. More importantly, a paradigm was thus set up, which has led to a diversity of research of the issue in the following years.

\section{INFLUENCE OF CULTURE ON ENGLISH LANGUAGE LEARNING}

\section{A. Existence of Cultural Differences}

Cultural differences fall into different categories. As professor Deng Yanchang (1989) suggests, the differences 
might be grouped according to four aspects: (1) a term in one language that does not have an equivalent in another language; (2) words or terms in both languages that appear to refer to the same object or concept on the surface, but which actually refer to quite different things: (3) things or concepts that are represented by one or perhaps two terms in one language, but by many more terms in the other language, that is, finer distinctions exist in the other language; (4) terms that have more or less the same primary meaning, but which have secondary or additional meanings that may differ considerably from each other.

Besides, cultural differences also exist in idioms, proverbs, sayings, allusions, taboos, etc. And failures to observe them often result in breakdown in intercultural communication. Additionally, attention should also be given to nonverbal communication. Although we may not realize it, when we converse with others we communicate by much more than words. By our expressions, gestures and other body movements, we send messages to those around us. But not all body language means the same thing in different cultures. Different peoples have different ways of making nonverbal communication. Hence, cultural differences also exist in body language, such as physical contact and eye contact between Chinese and English native speakers.

\section{B. Influences of Cultural Differences on English Language Learning}

Intercultural communication occurs whenever people from different cultural backgrounds come into contact with each other. Because of cultural differences, misunderstandings and miscommunication may arise in spite of grammatically correct utterances. The same words or expressions may not mean the same thing to people from different cultures. A serious question may not cause seriousness, and a happy statement may cause unhappiness or anger because of cultural differences. Therefore, students have to master the knowledge of cultural differences so as to achieve appropriate intercultural communication and avoid pragmatic failures.

Thomas points out that interference in communication is generally referred to as pragmatic failure, which has nothing to do with grammatical mistakes but comes from inappropriate ways of speaking or the unconventional expressions resulting from different perceptions of what is considered as appropriate linguistic behavior. According to Thomas, pragmatic failure falls into two types: pragmalinguistic failure and sociopragmatic failure.

Pragmalinguistic failure is the wrong use of the language itself, including incorrect use of English language and one's mother tongue. Here is an example:

A: Thanks a lot. That's a great help.

B: Never mind

The meaning, that B intends to express, is "Not at all" or "That's all Right". But influenced by the Chinese way of expressing in the same situation, he uses "Never mind", whose literal meaning is similar to the response to "thanks" in Chinese culture. However, the English expression "Never mind" is actually used as a response to the expressing of an apology of the other side.

Sociopragmatic failure results from different cultural norms and pragmatic principles that govern linguistic behaviors in different cultures. Sociopragmatic failure finds its way in many aspects of daily communication, such as ways of greeting and addressing people, ways of expressing modesty and apology, inquiring or offering, bidding farewell or making introduction, and views of value systems like privacy, etc. Sociopragmatic failures may directly lead to serious misunderstanding or even breakdown in intercultural communication.

From the example mentioned above, we can see that misunderstandings do exist in intercultural communication. Cultural differences between English and Chinese languages lead to different assumption of what constitute appropriate linguistic behaviors. The lack of knowledge about target cultural traits is the main cause of those pragmatic failures.

After the research, professor Hu Wenzhong (2002) draws a conclusion: An analysis of the students' "cultural mistakes" shows that some are obvious errors which can be put right fairly easily while those that have to do with values, beliefs and concepts require a great deal of work over a period of time. Whatever the case may be, the respondents' feedback has confirmed my belief that "cultural mistakes" are often worse than linguistic ones and tend to create ill feeling between native speakers and Chinese speakers of English.

\section{Understanding of Cultural Differences}

As mentioned above, examples of pragmatic failures and cultural mistakes can be found far and wide in intercultural communication, and some may be more serious. When learning English, we couldn't take no notice of the cultural difference between China and the west countries.

One major reason of the students' cultural mistakes is that whether our teaching or our teaching materials all attach importance to language forms instead of the social meanings of language or the application of language in authentic situations. For example, many texts contain the "dialogues" like this:

-- What's your name?

-- My name is Sun Li.

-- How old are you?

-- I'm eighteen.

-- Where are you from?

-- I am from Shanghai.

-- Where are you going? 
-- I'm going to the library.

$\ldots$

The dialogues above are made up by "Chinese ideas + English forms". Though the forms are correct, appropriateness is neglected. In fact, the English native Speakers' psychological response to such questions as Where do you come from? is Why do you ask? or even It's none of your business. Unfortunately, little attention is paid to the cultural and psychological differences in our teaching materials and students just imitate and use mechanically what they have learned regardless of all the explicit and implicit differences existing in the two languages and cultures.

So awareness of cultural differences and recognizing where cultural differences are at work is the first step toward understanding each other and establishing a positive working environment. In a word, we should be clearly aware of the influence of culture on our English language learning and attach importance to not only language teaching, but also culture teaching.

\section{CONTENT OF CUlture Teaching}

Wang Zhenya divides intercultural communication into three forms by means of different media: verbal interaction, non-verbal interaction and extra-verbal interaction.

\section{A. Verbal Communication}

Since language is a means of verbal communication and we mainly depend on language to communicate with each other, verbal communication is also vitally important in intercultural communication. So in our culture teaching we should focus more on this important component. Three aspects of verbal communication will be covered here: words and idioms, grammar and discourse.

1. Words and Idioms

Words and idioms are the most culturally-loaded element in language. The material civilizations, social institutions and spiritual beliefs of a nation are firstly reflected in words and phrases and idioms. We should pay more attention to them when we introduce cultural knowledge to the students in class.

Idioms are fixed structures including set phrases, proverbs, sayings and slang. Idioms are gems of languages and reflect lives of people. Idioms are culture-specific. They carry cultural connotations and meanings and are associated with historical background, economic life, geographical surroundings, religions, customs, thought patterns and value orientations. Both Chinese and English have a huge amount of idioms, and most of them reflect the specific characteristics of Chinese culture and English culture. For example, attitudes towards dog are greatly different in Chinese and English. In Chinese dog is a kind of humble animal and idioms related to dog mostly have derogatory sense. While in the western countries, dog is regarded as the most loyal friend of human beings and most idioms concerning dog don't have derogatory sense. For example, you are a lucky dog. Every dog has his day. Love me, love my dog.

2. Grammar

Differences in sentence structures often give rise to certain difficulties in language learning, teaching, translation, and intercultural communication. Language gives structure to experience, and helps to determine our way of looking at things, so that it requires some intellectual effort to see them in any other ways than that which our language suggests to us. In different languages the ways in which language components are organized insentience might be different. The typical complex sentences in English look like trees with trunks, branches, twists and leaves at different levels. The branches are generally introduced by relative pronouns, non-infinite verbs, prepositions, subordinate conjunctions, etc, explicitly marking their subordinate status. In contrast, holistic thinking, which is to view an event as a whole, has been an important aspect of Chinese culture.

In addition, there are differences in word order between the two languages. In English items representing the smallest units or the individual parts precede those representing the bigger units or the whole. While in Chinese, it is just the opposite.

3. Discourse

The term "discourse" refers to any piece of spoken or written language, which expresses a complete meaning. Discourses, like words, phrases and sentences, are language units. There are also some cultural differences concerning the organization of discourses in different languages. The American scholar, Kaplan found that typical English writing style is like a straight line with topic sentences at the very beginning of each paragraph, followed by developing sentences and concluding sentences at last, or illustrative sentences at first, ending up with topic sentences. While the typical writing style of the students whose mother tongues are oriental languages including Chinese is like a helix, that's to say, they don't go directly to the theme of the discourse, but demonstrate it indirectly. The English native speakers are usually greatly puzzled by this type of writing.

In Kaplan' opinion, different modes of written discourses indicate different cultural thought patterns. Differences in writing English compositions arise from the negative transfer of students' native languages.

\section{B. Non-verbal Communication}

Although we place more emphasis on verbal communication, we can't take no notice of non-verbal communication. 
A smile and an outstretched hand show welcome. A frown is a sign of displeasure. Nodding one's head means agreement- "Yes". But nonverbal behaviors are spontaneous, fleeting, and often beyond people's consciousness and control. Samovar and Porter say, "all human beings use nonverbal symbols to share their thoughts and feelings. Although the process of using our actions to communicate is universal, the meanings for those actions often shift from culture to culture. Hence, nonverbal communication becomes another element one must understand if one is going to interact with people from different cultures." If we cannot understand the non-verbal behaviors of native speakers, misunderstandings will appear. Now let's just look at some important aspects of non-verbal interaction.

\section{Spatial Concept}

The study of how human beings use space to communicate is called proxemics. Spatial concept concerns how people transmit information through body distance in communication. The way in which people use space is determined by their cultural orientation, age, social status and sex. An American may be upset when his private space is violated. While in China, since most of Chinese are brought up to share space with their brothers and sisters, people do not value privacy as important as the westerners. When they converse, they tend to stand closer than the westerners do. Therefore, when conversing with the English native speakers, the important thing we must keep in mind is that they do not like people to be too close. Being to far apart, of course, may be awkward, but being too close makes people uncomfortable.

2. Physical Contact

The appropriateness of physical contact varies with different cultures. In English speaking countries, physical contact is generally avoided in conversation among ordinary friends or acquaintances. Merely touching someone may cause an unpleasant reaction. If one touches another person accidentally, he/she usually makes an apology.

In China when we see babies or very small children, we often fondle them. The Chinese mothers can't become unhappy because of our behavior -- whether touching, patting, hugging of kissing their children. In their opinions, such gestures are merely signs if friendliness or affection. On the contrary, such actions in the English culture would be considered rude, intrusive, and offensive and could arouse a strong dislike and even repugnance.

3. Eye Contact

Eye contact is an important aspect of body language. One could draw up quite a list of "rules" about eye contact: to look or not to look; when to look and how long to look; who and who not to look at.

American custom demands that there should be eye contact in conversation with people who know each other. This applies to both the speaker and the listener. For either one not to look at the other person could imply a number of things, among which are fear, contempt, uneasiness, guilt, indifference. Even in public speaking there should be plenty of eye contact. But if a Chinese speaker is in the habit of doing, he would be regarded as inconsiderate and disrespectful.

In short, there are some other means of non-verbal communication, such as facial expression, posture, gesture, etc. Taking no notice of them is impossible. For example, gestures can be particularly troublesome, for a slight difference in making the gesture itself can mean something quite different from that intended. A wrong interpretation of a gesture can arouse quite unexpected reactions.

\section{Extra-verbal Communication}

Besides verbal and non-verbal communication, there exists another one, which we can refer to as extra-verbal communication. Extra-verbal communication is closely related to verbal and non-verbal communication and they are often intertwined together. Now it will be discussed from three aspects: communicative customs and etiquettes; social institutions and interpersonal relationships; and value orientations.

1. Communicative Customs and Etiquettes

Communicative customs and etiquettes refer to a set of rules or habits that all certain cultural members follow in their interactivities, including not only verbal actions, such as greetings and farewells; ways of address; compliments and praise, etc., but also complex communicative activities, such as visiting friends, giving someone a ring and shopping, etc. Here I'll mainly talk about visiting friends or being a guest, and giving somebody a present.

2. Social Institutions and Interpersonal Relationships

Interpersonal relationships involve familial relationship, relationship between friends and colleagues. Family is the most basic unit of our society and it is also a prevalent phenomenon of today's human culture. Nevertheless, in different countries and nations, the familial structures are not always the same. As Chinese, we all know that our Chinese people have a strong familial concept and the relationship between family members is very close. Though more and more young couples choose to live in their own houses, they will live with their parents after their babies are born or after their parents are old enough in order to look after each other. On the other hand, parents and children are greatly dependent on each other in terms of money.

3. Value Orientations

There are remarkable differences between the easterners' and the westerners' value orientations resulting from their respective traditional cultures. Chinese culture is known for its fine traditional standards of humility, comity, and sense of collective responsibility, etc.

In short, since culture is an extremely complex concept and an enormous subject, and it embraces almost everything in the world, whether material or spiritual, it's a challenging task for us to teach the target culture. What I mentioned above is just a part of the content of culture teaching and there are also some other aspects that we should pay attention 
to in culture teaching. Of course, culture teaching can't be separated from language teaching and as English teachers, we should also adopt some practical techniques to teach culture.

\section{TeChniques of Culture Teaching}

From the mid of 1960s, especially after 1970s, culture teaching scholars introduced a series of techniques of teaching culture in classroom. The most important ones are briefly as follows.

\section{A. Comparative Method}

It refers to the teacher introducing one or more items in the home and target culture before discussion class and then indicating the differences between them. In class the teacher and students discuss the possible problems in language communication resulting from the cultural differences.

\section{B. Culture Aside}

It refers to the introduction and discussion of culture during the teaching of language. For example, when involving the information about Thanksgiving Day during language teaching, the teacher can present the origin, ways of celebration and customs, etc. of Thanksgiving Day incidentally.

\section{Culture Capsule}

A culture capsule is a short description given by the teacher orally, usually one or two paragraphs in length, of one minimal difference, misunderstanding or conflict in intercultural communication, accompanied by illustrative photos, slides, or realia. Then a series of questions are given to be discussed in class. The technique can be used for independent study, in small groups, or within the full class.

\section{Culture Island}

Culture island refers to the placards, photographs, blackboard newspaper that are used to attract the students' attention and discussion of the target culture. At any rate, the foreign language classroom should become a "cultural island", where the accent will be on "cultural experience" rather than "cultural awareness". From the first day, teachers are expected to bring in the class posters, pictures, maps, and other realia in order to help students develop "a mental image" of the target culture.

\section{E. Mini-drama}

A mini-drama can be constructed from three to five episodes in which a cultural conflict or miscommunication occurs. As each episode is experienced, students attempt to explain what the source of the miscommunication is through class discussion, led by the teacher. After each episode in the series, more cultural information is given, but not enough to identify the precise cause of the problem, which becomes apparent only in the last scene. Seelye (1985) explains that function of this technique is to lead students to experiencing the vagueness of much intercultural communication due to differing assumptions in the two cultures about the connotation of words or about everyday events and practices. Students see how they might easily jump to false conclusion about the people in the target culture because they are reacting on the basis of their own ethnocentric biases and perceptions.

Of course, there are also some other techniques, such as culture clusters, culture pervasion, literature analysis, ethnographic techniques training, deriving cultural connotations, hypothesis refinement and artifact study, etc.

The techniques of teaching culture mentioned above have been proposed since the early 1970s and have been tried and tested by classroom teachers. Selection of instructional ideas from among these techniques should be guided by the level of cultural awareness and sophistication of the students, as well as by their level of linguistic proficiency, especially in the case of those activities that draw on textual materials.

\section{CONCLUSION}

With the development of science and technology and the globalization of world economy, the communication between various cultures has become closer and more frequent. The intercultural communication has become one of the themes of modem society, which calls for the emergence of culture teaching. The teaching of culture should become an integral part of foreign language instruction. People from different cultures weave their lives into an international fabric that is beginning to fray at the edges by virtue of miscommunication and propaganda. In order to avoid this ignominious cultural and political disintegration, and foster empathy and understanding, teachers should "present students with a true picture or representation of another culture and language". And this will be achieved only if cultural awareness is viewed as something more than merely a compartmentalized subject within the foreign language curriculum; that is, when culture "inhabits" the classroom and undergirds every language activity. After all, culture teaching is vitally important, applicable, and challenging.

\section{REFERENCES}

[1] Deng Yanchang \& Liu Runqing. (1989). Language and Culture. Beijing: Foreign Language Teaching and Research Publishing 
House.

[2] Halverson, R. J. (1995). Culture and Vocabulary Acquisition: A Proposal. Foreign Language Annals, 18(4) 63-69.

[3] Hu Wenzhong, Gao Yihong. (1997). Foreign Language Teaching and Culture. Changsha: Hunan Education Press.

[4] Hu Wenzhong. (2002). Transcend Cultural Barrier - Hu Wenzhong Comparative Cultures Analects (Revised Edition). Beijing: Foreign Language Teaching and Research Publishing House.

[5] Hu Zhuanglin. (2006). Linguistics: A Course Book. Beijing: Beijing University Press.

[6] Kohls, L. R., \& J. M. Knight. (1994). Developing Intercultural Awareness: A Cross-cultural Training Handbook. Yarmouth, ME: Intercultural Press.

[7] Kramsch, Claire. (2005). Context and Culture in Language Teaching. Oxford: Oxford University Press.

[8] Samovar, L. A. \& R. E. Porter. (1995). Communication between Cultures. Belmont, CA: Wadsworth. Publishing Company.

[9] Samovar, L. A. \& R. E. Porter. (1998). Intercultural Communication: A Reader. Belmont CA: Wadsworth Publishing Co.

[10] Seelye, H. Ned. (1985). Teaching Culture: Strategies for Intercultural Communication. Lincolnwood Illinois: National Textbook.

[11] Singhal. (1998). Teaching Culture in the Foreign Language Classroom. Thai TESOL Bulletin, Vol. 11 No. 1, February, $16-17$.

[12] Williams, Raymond. (1983). Keywords: A Vocabulary of Culture and Society. Oxford: Fontana Press.

Liangguang Huang was born in Danyang, China in 1975. He received his B.A. degree in Foreign Linguistics and Applied Linguistics from Jiangsu University, China in 1997.

He is currently a lecturer in English Department, Zhenjiang Watercraft College of PLA, Zhenjiang, China. His research interests include Second Language Acquisition and Foreign Language Teaching.

Runjiang Xu was born in Zhenjiang, China in 1984. She received her M.A. degree in Foreign Linguistics and Applied Linguistics from Jiangsu University, China in 2010.

She is currently a lecturer in English Department, Zhenjiang Watercraft College of PLA, Zhenjiang, China. Her research interests include Second Language Acquisition and Foreign Language Teaching. 